\title{
SUA VIDA É UM LIVRO: UM TRABALHO INTERDISCIPLINAR ACERCA DO PAPEL DA MULHER NA COMUNIDADE

\author{
Caio Vinicius Corrêa Nunes ${ }^{1}$ \\ Marina Mulinari Peixoto ${ }^{2}$ \\ Pedro Henrique Pereira da Silva ${ }^{3}$ \\ Vagner Matias da Silva ${ }^{4}$
}

Resumo: Este estudo visa abordar os aspectos políticos, culturais e históricos da sociedade, com ênfase na importância do papel da mulher. A fundamentação teórica foi construída à luz dos Parâmetros Curriculares Nacionais do Ensino Médio (2006), do Currículo do Estado de São Paulo (2011) e Lustosa (2006). Tendo em vista que o ensino médio atual deve se preocupar com uma educação permanente, o que significa preparar o aluno para a vida e qualificá-lo para a cidadania, seja num futuro ambiente escolar ou profissional, espera-se que o aluno, ao realizar as atividades propostas neste projeto, adquira um significado ao seu aprendizado e reconheça a importância da figura feminina na sua sociedade. Para tanto, foi elaborado um projeto interdisciplinar entre as áreas de Linguagens, Códigos e suas Tecnologias e Ciências Humanas a fim de organizar um trabalho em que o conhecimento seja contextualizado de forma sincrônica, diacrônica e interativa.

Palavras-chave: Interdisciplinar; Linguagens e códigos; Mulher; Biografia.

\footnotetext{
${ }^{1}$ Centro Universitário UNIFATEA, Brasil. E-mail: caiovcnunes@gmail.com.

2 Centro Universitário UNIFATEA, Brasil. E-mail: m.mulinari@hotmail.com.

${ }^{3}$ Centro Universitário UNIFATEA, Brasil. E-mail: ph.pedrohsilva@gmail.com.

${ }^{4}$ Centro Universitário UNIFATEA, Brasil. E-mail: vagner_matias@hotmail.com.
} 